\title{
Policing for London
}

\author{
by Marian Fitzgerald, Mike Hough, lan Joseph and Tareq Qureshi \\ Cullompton: Willan (2002) ISBN 190324093 X \\ (166 pages, £15.00)
}

\section{Reviewed by J.R. Benton}

Those seeking sensational revelations about the policies or performance of the Metropolitan Police Service (MPS) will be disappointed by this book. Rather, it is a diligently researched picture of the current state of Londons policing and public perceptions of it, no less valuable for confirming much that we already knew or at least suspected. For example few would be surprised to learn that 59 per cent of the (weighted) public sample interviewed thought that 'more bobbies on the beat' should be Scotland Yard's number one priority.

Three eminent foundations undertook the independent study upon which the book is based: the Nuffield, the Esmee Fairbairn and the Peter Hamlyn. Their diligence is praiseworthy, and the principles forming the basis of the copious tables and graphs are clearly explained. Flesh is added to the bones of the data by an orderly and well-written progression through ten chapters, the last of which summarises conclusions against a background of comparisons with the environment within which the MPS worked twenty years ago. Since that time London has inexorably moved ever closer to the New York scene of drugs, guns, or ganised crime, ethnic strife and an anti-authority culture. This trend is seen as bound to continue and to demand some fundamental changes in the policies and practices of the police.

Particular stress is laid on responsiveness and on partnership with the public. Responsiveness must include first response to intruder alarms, which is a bone of contention at present, and in the context of partnership a brief reference is made to the Police/Community Consultative Groups (PCCGs) which were set up following the Scarman Report in most inner -city boroughs. This reviewer has served on the Brent Group since its inception, and whilst we have had our fair share of crime in this most multi-ethnic borough we have not had any serious race rioting. PCCGs represent established channels readily available and supported by the police. Steps are being taken to strengthen and expand them.

Scant reference is made to the many and varied ways in which technology and the (now regulated) security industry have already relieved the police of onerous burdens and aided performance. DNA testing, for example, has enormously helped in the detection of crime. CCTV systems, given greater co-ordination of municipal or corporate surveillance and police control rooms, could reap substantial benefits in reducing petty crime and disorder Such tasks as the transport of prisoners are now entrusted to the private sector, and more of the same could increasingly save the time and enhance the status of the trained professional policeman.

Chapter 10 gives a strong and timely warning against excessive emphasis on quantitative performance measurement as against qualitative service assessment, and also condemns what is defined as 'public sector managerialism'. In a word, it advocates firm and fair policing with a human face. This is easy to say but very difficult to achieve. 


\section{Security Journal}

Apart from the omission of an index (odd in a book so certain to attract frequent reference) 'Policing for London' is an excellent and most useful publication which one hopes will grace the shelves of every senior police of ficer and be available to all ranks - especially recruits.

Likewise it should be read by all politicians and professionals concerned with the good governance of our capital city.

J.R. Benton

Association of Security Consultants Ltd 